\title{
PENGARUH LATIHAN MEMUKUL BOLA GANTUNG TERHADAP KEMAMPUAN JUMP SERVICE ATLET PUTRA CLUB CAROLINE KOTA LUBUKLINGGAU PROVINSI SUMATERA SELATAN
}

\author{
Marcelina Garcia Ana \\ PENJAS FKIP UNIB, e-mail: garciaanamarcelina@gmail.com \\ Sugiyanto \\ Universitas Bengkulu \\ Defliyanto \\ Universitas Bengkulu
}

\begin{abstract}
Abstrak
Penelitian ini bertujuan untuk mengungkapkan pengaruh latihan memukul bola gantung terhadap kemampuan jump service atlet putra Club CAROLINE Kota Lubuklinggau Provinsi Sumatera Selatan. Adapun rumusan masalah dalam penelitian ini adalah Apakah ada pengaruh latihan memukul bola gantung terhadap kemampuan jump service atlet putra Club CAROLINE Kota Lubuklinggau Provinsi Sumatera Selatan. Penelitian ini dilakukan di club CAROLINE kota lubuk linggau provinsi Sumatera Selatan pada tahun 2017. Metode penelitian yang digunakan Quasi Eksperimen Design yaitu dengan menggunakan rancangan One-group Preetest-posttest design, penelitian ini secara objektif atau apa adanya dengan sampel 18 orang atlet dengan cara menjadikan semua populasi menjadi sampel (total sampling). Adapun hasil data terbukti $t$ hitung $<\mathrm{t}$ table $(-4,1<1,740)$ artinya terbukti bahwa ada pengaruh yang signifikan latihan memukul bola gantung terhadap kemampuan jump service bola voli, sedangkan perentase latihan memukul bola gantung berpengaruh terhadap jump service yaitu sebesar $(16,81 \%)$.
\end{abstract}

Kata kunci: Bola Gantung, dan Jump Service

\begin{abstract}
This study aims to reveal the effect of hammer ball training on the ability of male athlete service jump club Club CAROLINE town Lubuklinggau South Sumatra Province. The formulation of the problem in this study is Is there any influence of the practice of hitting the ball hanging ability to jump service men's club athlete CAROLINE Lubuklinggau South Sumatera Province. The study was conducted at the club CAROLINE town lubuklinggau South Sumatra province in 2017. The research method used Quasi Eksperimen Design is using One-group design Preetest-posttest design, this research is objective or what it is with the sample of 18 people athletes by making all the population into sample (total sampling). The results of the data proved $t$ count $<t$ table ($4.1<1.740$ ) It means that there is a significant effect of hammer ball training on the ability of volleyball service jump, while the percentage of drills hanging ball exercise affect the jump service that is equal to (16.18\%).
\end{abstract}

Keywords: Hanging Ball, Jump Service. 


\section{PENDAHULUAN}

Sumber daya manusia yang berkualitas di antaranya ditandai dengan peningkatan kesehatan jasmani dan rohani yang sehat, berkepribadian disiplin, dan sportivitas yang tinggi sehingga dapat membawa rasa kebanggaan nasional. Pentingnya pengembangan dan pembinaan di bidang olahraga ini tercantum dalam UU RI No. 3 tahun 2005 tentang keolahragaan yang menyatakan : bahwa mencerdaskan kehidupan bangsa melalui instrument pembangunan Nasional di bidang keolahragaan merupakan upaya meningkatkan kualitas hidup manusia Indonesia secara jasmaniah, rohaniah, dan sosial dalam mewujudkan masyarakat yang maju, adil, makmur, sejahtera, dan demokratis berdasarkan Pancasila dan Undang-Undang Dasar Negara Republik Indonesia tahun 1945 (Asraini,2011:2).

Prestasi dapat dicapai bila didukung kemampuan kondisi fisik, teknik, strategi, taktik, dan mental. Syafruddin (2011:54) menyatakan bahwa, "kondisi fisik (physical condition) merupakan unsur atau kemampuan dasar (basic ability) yang harus dimiliki setiap atlet untuk meraih suatu prestasi olahraga" Oleh karena itu, setiap program latihan yang dilakukan adalah mengembangkan komponen-komponen kondisi yang terkait secara umum maupun spesifik. Hal ini didukung oleh pendapat Blume (2004:22) yang menyatakan bahwa, "kemampuan teknik dan taktik seseorang pemain bolavoli ditentukan oleh komponen-komponen kekuatan, daya tahan, kecepatan, kelentukan, dan koordinasi. Hal senada juga dikatakan oleh Maidarman (2009) bahwa, "peningkatan kondisi fisik atlet bertujuan agar kemampuan fisik menjadi prima dan berguna untuk menunjang aktifitas olahraga dalam rangka mencapai prestasi prima". Selain itu, tinggi rendahnya keterampilan seseorang dalam bermain bolavoli juga dipengaruhi oleh faktor lain di antaranya motivasi, minat, bakat, sarana dan prasarana, dan metode latihan gerak. Semua faktor ini berhubungan antara satu dengan yang lainnya. Maka, bagi seorang pelatih untuk dapat memperhatikan kondisi fisik dalam pencapaian prestasi dan ketepatan teknik dasar permainan bolavoli seperti service, passing, block, dan smash. Untuk meningkatkan jump service atlet putra Club CAROLINE Kota Lubuklinggau bisa dilakukan dengan menggunakan bentuk-bentuk latihan peningkatan kemampuan jump service itu sendiri. Salah satu bentuk latihan guna meningkatkan kemampuan jump service adalah latihan bola gantung. Kemampuan jump service sangat penting dalam cabang olahraga bola voli, maka usaha-usaha untuk mencapai kemampuan jump service, harus dijalankan dengan struktur latihan yang terprogram dengan baik, serta diperlukan keseriusan dan motivasi dari atlet itu sendiri dalam menjalankan latihan, agar hasil yang diinginkan dalam peningkatan kemampuan jump service dapat tercapai semaksimal mungkin. Berdasarkan bentuk latihan yang dikemukakan di atas, dalam usaha memperbaiki dan meningkatkan kemampuan jump service atlet putra Club CAROLINE Kota Lubuklinggau Provinsi Sumatera Selatan. Maka peneliti tertarik untuk melakukan penelitian yang berhubungan dengan permasalahan di club CAROLINE Kota Lubuklinggau Provinsi Sumatera Selatan. Berdasarkan penjelasan diidentifikasi beberapa masalah sebagai berikut : 1) Kurangnya motivasi atlet berpengaruh terhadap kemampuan jump service atlet putra Club CAROLINE kota Lubuklinggau Provinsi Sumatera Selatan. 2) 
Kurangnya sarana dan prasarana berpengaruh terhadap kemampuan jump service atlet putra Club CAROLINE kota Lubuklinggau Provinsi Sumatera Selatan. 3) Belum diadakannya latihan bola gantung untuk meningkatkan kemampuan jump service atlet putra Club CAROLINE kota Lubuklinggau Provinsi Sumatera Selatan. Berdasarkan banyak masalah maka penelitian membatasi penelitian tentang pengaruh latihan memukul bola gantung terhadap kemampuan jump service atlet putra Club CAROLINE Kota Lubuklinggau Provinsi Sumatera Selatan. Kemudian permasalahan tersebut dirumuskan Apakah ada pengaruh latihan memukul bola gantung terhadap kemampuan jump service atlet putra Club CAROLINE Kota Lubuklinggau Provinsi Sumatera Selatan?. Sedangkan tujuan yang diharapkan dalam penelitian ini adalah untuk mengungkapkan pengaruh latihan memukul bola gantung terhadap kemampuan jump service atlet putra Club CAROLINE Kota Lubuklinggau Provinsi Sumatera Selatan. Dan manfaat yang didapatkan dalam penelitian ini yaitu 1) Masukan bagi pelatih bola voli CAROLINE Kota Lubuklinggau dalam mengembangkan jump service atlet. 2) Bagi atlit putra bola voli club CAROLINE kota Lubuklinggau untuk meningkatkan kemampuan jump service. 3) Bagi pembaca Sebagi bahan bacaaan di perpustakaan. 4) Bagi peneliti dapat mengembangkan kemampuan lebih jauh lagi tentang bola voli khususnya jump service.

\section{METODE}

Penelitian ini merupakan Quasi
Eksperimen Desingn yaitu dengan
menggunakan rancangan One-groub Preetest-
posttest desing. Sampel yang digunakan
adalah 18 atlit putra Club CAROLINE Kota
Lubuklinggau Provinsi Sumatra Selatan,
Kemudian dilakukan preetest atau tes awal,

setelah itu atlit diberi prlakuan/tretmen dan diahkiri dengan posttest atau tes ahkir.

Populasi pada penelitian ini adalah atlet putra Club CAROLINE Kota Lubuklinggau Provinsi Sumatera Selatan yang terdaftar mengikuti latihan. CAROLINE merupakan club binaan dari PBVSI Kota Lubuklinggau Provinsi Sumatera Selatan. Atlit putra club CAROLINE Kota Lubuklinggau yang berjumlah 18 orang . Sampel dalam penelitian ini dimana anggota Club dijadikan sampel (total sampling). Hal ini sesuai dengan kaidah pengambilan sampel yang diutarakan oleh Sugiyono (2007) yang menyatakan jika jumlah populasi hanya sedikit maka diambil semua.

Sesuai dengan maksud dan tujuan penelitian ini, maka dalam pengumpulan data terlebih dahulu dilakukan pengukuran variabel dependen dengan pengujian tes awal (pretest), diikuti dengan memberikan treatment/stimulus ke dalam kelompok yang diteliti, dan diakhiri dengan mengukur kembali variabel dependen setelah diberikan stimulus (post-test) (Prasetyo dan Jannah, 2005:159). Tes awal bertujuan untuk mengetahui data awal kemampuan jump service sebelum sampel mendapatkan perlakuan. Tes akhir bertujuan untuk mengetahui peningkatan kemampuan jump service setelah sampel mendapatkan perlakuan selama satu setengah bulan atau 16 kali pertemuan dengan frekuensi latihan 3 kali dalam seminggu.

Data yang diperlukan dalam penelitian ini adalah nilai kemampuan jump service bolavoli. Tes yang digunakan dalam penelitian ini adalah serving test, Nilai validasi instrumen jump service 0,68 dan reliabelitas 0,85 (Arsil, 2009:132-133). Adapun langkah-langkah pelaksanaan serving test menurut Arsil (2009:133-134) adalah sebagai berikut : a).Teste berdiri dibelakang garis kotak service menghadap daerah sasaran yang ada dilapangan sebelah, b). Lalu melakukan service kedaerah sasaran. c). Setiap bola yang masuk 
sasaran diberi nilai sesuai sekor sasaran. d. Bola yang menyentuh net dianggap satu pukulan tapi tidak diberi nilai. e). Teste tidak boleh menginjak garis. f). Setiap jenis pukulan diperbolehkan asal sesuai dengan peraturan bola voli. g). Setiap bola yang jatuh pada garis batas daerah sasaran di beri sekor daerah sasaran yang lebih besar. h). Teste melakukan 10 kali service tiap pelaksanaan. Penilaian: Nilai seorang testee dalam serving test adalah jumlah yang terbaik untuk 10 kali service dalam satu kali pelaksanaan. Alat dan perlengkapan yang digunakan dalam penelitian ini adalah : Bola voli, Lapangan bolavoli Meteran, Net, Kapur putih dan alatalat tulis.

\section{HASIL DAN PEMBAHASAN}

Hasil

Berdasarkan hasil penjelasan serta uraian yang telah dikumpulkan sebelumnya, maka pada bab ini akan mencari hasil penelitian analisis data dan pembahasan yang diperoleh dengan menggunakan statistik. Dari satu kelompok yang dijadikan kelompok eksperimen memukul bola gantung. Semua data yaitu 18 sampel memenuhi persyaratan untuk diolah dalam penelitian ini. Dari hasil penelitian yang dilakukan di dapatkan hasil dari tes awal dan akhir beseta dengan uji prasyarat yaitu normalitas dan homogenitas.

Tes awal

Hasil penelitian menunjukkan bahwa distribusi skor tes awal kemampuan jump servis yang diukur dengan menggunakan serving test sebanyak 10 kali service tiap pelaksanaan. Berdasarkan hasil tes pre-test diperoleh ratarata hitung $=20,30$, standar deviasi $=4,21$, nilai minimum $=12$, dan maksimum $=28$.

Tes akhir

Hasil penelitian menunjukkan bahwa distribusi skor tes akhir kemampuan jump servis yang diukur dengan menggunakan serving test test sebanyak 10 kali tiap pelaksanaan. Berdasarkan hasil tes post-test diperoleh ratarata hitung $=26,88$, standar diviasi $=4,30$, nilai minimum $=19$, nilai maksimum $=34$.

Dalam penelitian ini ada satu hipotesis penelitian, yaitu: terdapat pengaruh yang signifikan antara latihan memukul bola gantung terhadap peningkatan kemampuan jump service atlet putra club CAROLINE Kota Lubuklinggau Provinsi Sumatera Selatan. Data pengukuran pre-test kemampuan jump service menggunakan latihan memukul bola gantung diperoleh rata-rata 20,30, sedangkan pada post-test diperoleh 26,88. Dasar pengambilan terima $\mathrm{H}_{\mathrm{a}}$ jika $t_{\text {hitung }}<t_{\text {tabel }}$ pada taraf signifikansi 0,05 dan dk=n-1 = 17 .

\section{Pembahasan}

Berdasarkan hasil analisis dan hipotesis diajukan, maka pada bagian ini akan dilakukan pembahasan terhadap temuan penelitian didapatkan di lapangan. Selanjutnya pembahasan dalam penelitian ini akan merujuk pada hipotesis yang diajukan. Dari hipotesis yang menyatakan bahwa terdapat pengaruh yang signifikan antara latihan memukul bola gantung terhadap peningkatan kemampuan jump service bolavoli. Hal ini dapat dilihat dari rata-rata peningkatan kemampuan jump service dalam 10 kali service tiap pelaksanaan melalui data tes awal (pretest) dan data tes akhir (post-test). Peningkatan rata-rata kemampuan jump service dalam 10 kali service tiap pelaksanaan dengan latihan memukul bola gantung, tes awalnya 20,30 meningkat menjadi 26,88 (meningkat 6,58 point). Selanjutnya dari hasil analisis yang menyatakan bahwa terdapat pengaruh yang signifikan antara latihan memukul bola gantung terhadap peningkatan kemampuan jump servis atlet putra club CAROLINE Kota Lubuklinggau Provinsi Sumatera Selatan ini dibuktikan dengan hasil analisis yang didapat $t_{\text {hitung }}=-4,1$ 
lebih kecil dari $t_{\text {tabel }}=1,740$. Bahwa latihan dengan memukul bola gantung dapat diterapkan dalam mempelajari kemampuan jump service bolavoli. Setelah diamati pada waktu penelitian, peneliti melihat latihan memukul bola gantung sangat diperlukan untuk meningkatkan kemampuan jump service. Dengan melakukan latihan memukul bola gantung yang panjang secara terprogram, sistematis, terarah, dan berkesinambungan maka akan meningkatkan kemampuan jump service. Tapi bagi atlet yang sering tidak hadir dalam pelaksanaan program latihan, maka peningkatan kemampuan jump service akan lebih rendah dibandingkan atlet yang selalu mengikuti program latihan memukul bola gantung. Di samping itu, juga diperlukan konsentrasi terhadap stimulasi yang datang dengan cepat. Semakin banyak atlet mengalami aktivitas gerak tentu unsur-unsur kemampuan motorik semakin terlatih. Kemampuan motorik merupakan kualitas kemampuan seseorang yang dapat mempermudah dalam melakukan keterampilan gerak. Untuk menilai kualitas keterampilan gerakan bisa dilihat melalui ciriciri koordiinasi gerakan yang ditampilkan. Menurut Schnabel dan Meinel dalam Syafruddin (2011:60) ada sembilan ciri-ciri koordinasi gerakan, yaitu : 1 . Struktur gerakan, 2. Irama gerakan, 3. Hubungan gerakan, 4. Luas gerakan, 5. Kelancaran gerakan, 6. Tempo gerakan, 7. Kekuatan gerakan, 8. Ketepatan gerakan, 9. Kekonstanan gerakan. Dari uraian di atas, dapat disimpulkan bahwa dalam melakukan latihan memukul bola gantung secara berkesinambungan, maka akan meningkatkan kemampuan jump service. Selain itu, masih ada faktor yang mempengaruhi seperti : sarana dan prasarana, dan motivasi juga sangat menentukan keberhasilan dalam melakukan latihan. Faktor-faktor ini juga tidak bisa diabaikan dalam upaya peningkatan kemampuan jump service

\section{PENUTUP}

\section{Simpulan}

Berdasarkan hasil penelitian yang dilakukan selama satu bulan terakhir dan dilakukan dalam tiga kali dalam seminggu dan pengujian hipotesis dengan mengolah data baik prasyarat maupun mencari perbandingan apakah ada peningkaan ataukah tidak dalam penelitian ini, dengan cara melakukan uji awal atau pre-test didapatkan hasil awal dan setelah dilakukan perlakuan maka diakhir dilakukan post-test atau tes akhir untuk mengetahui adakah peningkatan atau tidak. Maka dapat ditarik kesimpulan yaitu terdapat pengaruh yang signifikan antara latihan memukul bola gantung terhadap kemampuan jump service atlet putra club CAROLINE kota lubuklinggau provinsi Sumatra Selatan. Dengan nilai thitung $<t_{\text {tabel }}(-4,1<1,740)$. Dengan demikian bola gantung berpengaruh terhadap jump service yaitu sebesar $(\mathbf{1 6 , 1 8 \% )}$.

\section{Saran}

Berdasarkan pada kesimpulan di atas, maka penulis dapat memberikan saran-saran yang diharapkan dapat membantu mengatasi masalah yang ditemui dalam meningkatkan kemampuan passing atas, di antaranya :

a. Bagi pelatih bola voli agar dapat memberikan materi yang tepat kepada pemain, khususnya untuk melatih teknik latihan modifikasi yang didukung oleh materi lainnya guna meningkatkan keterampilan jimp service sehingga dapat mendukung dalam memaksimalkan service.

b. Bagi atlet agar dapat mengembangkan keterampilan service khususnya jump 
service berdasarkan analisis yang telah diteliti dalam penelitian ini.

c. Bagi dosen atau guru pendidikan jasmani dan olahraga kiranya dapat menganalisa variabel-variabel lain untuk meningkatkan keterampilan jump service dalam bola voli

d. Bagi peneliti yang ingin melanjutkan penelitian ini agar dapat menjadikan penelitian ini sebagai bahan informasi, reverensi dan peneliti dengan populasi atau sampel yang berbeda dan dalam jumlah yang lebih banyak lagi.

\section{DAFTAR PUSTAKA}

Arsil. 2000. Pembentukan Kondisi Fisik. Padang: FIK UNP.

Asraini, 2003. Hubungan Kekuatan Otot JariJari Tangan dan Koordinasi MataTangan Terhadap Kemampuan Passing Atas Dalam Permainan Bola Voli Siswa SMK N 2 Pariaman. Padang: FIK UNP.

Blume, Gunter. 2004. Permainan Bola Voli (Training-Teknik-Taktik). Padang: FIK UNP.

Edwan, Ari, dan Bogy. 2017. "Pengaruh Metode Latihan Plyometric Terhadap Kemampuan Jumping Smash Bola Voli Siswa Ekstrakurikuler SMPN 1 Bermani Ilir Kabupaten Kepahiang" Jurnal Kinestetik, Vol. 1 (1).

Maidarman. 2009. Tes Pengukuran Dan Evaluasi Melatih Kondisi Fisik. Padang: FIK UNP.

Prasetyo, Jannah. 2005. Metode Penelitian Kuantitatif. Jakarta: PT RajaGrafindo Persada.

Sugiyono. 2007. Metode Penelitian Kuantitatif. Bandung: Alfabeta

Syafruddin. 2011. Ilmu Kepelatihan Olahraga. Padang: UNP Press.
Tangkudung, James. (2012). Kepelatihan Olahraga Pembinaan Prestasi Olahraga. Jakarta: Cerdas jaya ,(2016).Macam-macam

Metodologi Penelitian. Jakarta: Lensa Media Pustaka Indonesia

,(2018). Sport Psychometrics

Dasar-dasar dan instrument Psikometri. Depok :Rajagrafindo persada

Yunus, M. 1992. Olahraga Pilihan Bolavoli. Jakarta: Depdikbud. 